\title{
SISTEM INFORMASI PERHITUNGAN KOMPOSISI BAHAN BAKU KERAMIK DENGAN METODE SIMPLEK PADA PT WHITE HORSE CERAMIC INDONESIA
}

\author{
${ }^{1}$ Dudi Awalludin, ${ }^{2}$ Ayu Agatha \\ STMIK Rosma Karawang \\ Email: dudi@rosma.ac.id
}

\begin{abstract}
ABSTRAK
Sistem informasi perhitungan komposisi bahan baku di PT White Horse Ceramic Indonesia merupakan salah satu sistem terpenting dalam proses produksi di perusahaan tersebut. Sistem yang sedang berjalan masih menggunakan aplikasi Microsoft Excel secara sederhana, sehingga pada saat melakukan perhitungan yang komplek akan memakan waktu yang cukup lama untuk mengetahui berapa kebutuhan bahan baku untuk memproduksi keramik yang sesuai dengan komposisi keramik. Setelah mengkaji dan melakukan analisis terhadap masalah, maka penentuan kebutuhan akan bahan baku produksi keramik akan lebih cepat dengan dibantu oleh sebuah system pendukung keputusan dalam menghitung komposisi keramik. Untuk perhitungan komposisi bahan baku keramik dengan menggunakan metode simpleks. Metode Simpleks termasuk dalam Model Pemograman Linear (Linear Programming). Linear Programming adalah suatu cara untuk menyelesaikan persoalan pengalokasian sumber-sumber yang terbatas di antara beberapa aktivitas yang bersaing, dengan cara yang terbaik yang mungkin dilakukan. Berdasarkan permasalahan yang terjadi, solusi untuk mengatasi masalah tersebut perlu dikembangkan suatu sistem informasi yang dapat digunakan dalm perhitungan penggunaan bahan baku terhadap komposisi keramik pengembangan sistem informasi menggunakan bahasa pemograman Microsoft Visual Basic.Net dengan basis data manajemen sistem Microsoft SQL Server 2008. Dengan diimplementasikannya sistem ini, diharapkan dapat membantu bagian perencanaan produksi dalam menentukan jumlah bahan baku yang akan digunakan oleh bagian produksi pada komposisi yang telah ditentukan sesuai dengan ukuran, type dan design keramik yang akan diproduksi lalu diteruskan ke bagian gudang untuk disiapkan material bahan baku tersebut.
\end{abstract}

Kata kunci: Sistem Pendukung Keputusan, Komposisi Keramik, Linear Programming.

\begin{abstract}
The information system calculation of raw material composition PT White Horse Ceramic Indonesia is one most important system in the production process at the company. The current system is still using Microsoft Excel with simple, resulting in the calculation of ineffective and inefficient due to take quite a long time for the calculation of the amount a ceramic composition. After the authors analyze the problem, then the decision support system (DSS) of ceramic composition is the right system for decided how many raw materials in accordance with the composition.

For the calculation of the ceramic composition, using the simplex method. Simplex method was included in the Linear Programming. Linear Programming is a means to resolve the issue of the allocation of limited resources among several competing activities, the best manner possible. Based on the problems that occurred as the author said above, to solve the problem need to be designed and implemented an information system calculation of raw material composition ceramic by using Microsoft Visual Studio 2008 programming and database using SQL Server 2008. With the implementation of this system, it will produce a command how many raw materials to be used in the composition of which has been determined in accordance with the size, type and design of ceramic to be produced and then forwarded to the warehouse to prepare the raw materials. In the future, the author expects the ceramic composition calculation process can be done with effective and efficient.
\end{abstract}

Keywords: Decision Support System, Composition Ceramic, Linear Programming.

\section{PENDAHULUAN}

Sistem informasi perhitungan komposisi bahan baku di PT White Horse Ceramic Indonesia merupakan salah satu sistem terpenting dalam sistem proses produksi di perusahaan tersebut. Sistem yang sedang berjalan masih menggunakan cara semi komputerisasi dengan menggunakan Microsoft Excel, sehingga mengakibatkan perhitungan yang memakan waktu yang cukup lama untuk perhitungan jumlah bahan baku sesuai dengan komposisi keramik. Dari hasil pengamatan, maka diperlukan sebuah sistem informasi yang dapat digunakan untuk menentukan berapa jumlah kebutuhan bahan baku pada suatu produksi keramik yang tepat sesuai dengan komposisi yang sudah 
ditetapkan. Sehingga diperlukannya pengembangan sistem dengan nama sistem informasi perhitungan komposisi bahan baku keramik.

\section{LANDASAN TEORI}

Pada saat ini masyarakat luas pada umumnya tidak asing dengan istilah sistem. Di lingkungan sekitar ini sebenarnya kita dikelilingi oleh berbagai sistem seperti, sistem bisnis, sistem pendidikan, sistem pemasaran, dan sistem transportasi. Sistem merupakan kumpulan dari sub sistem dalam suatu organisasi/perusahaan yang saling bersinergi untuk mencapai suatu tujuan dari organisasi/perusahaan.

Salah satu hasil dari suatu sistem adalah informasi dimana informasi tersebut diberikan kepada pihak ketiga. Sedangan informasi yang didapat dari pihak luar merupakan feedback dari konsumen untuk organisasi/perusahan yang nantinya akan digunakan untuk memperbaiki organisasi ataupun dipergunakan untuk meningkatkan kualitas suatu produk. Pihak manajemen dalam memutuskan suatu masalah agar menghasilkan keputusan yang baik salah satu metode digunakan Riset Operasi dengan linear programming.

Menurut Frederick S. Hiller dan Gerald J. Lieberman dalam buku Reset Operasi Johanes Supranto (2009) "Operations research may be described as a scientific approach to decision making that involves the operations of organizational system".

Menurut Shiv K. Gupta dan John M. Cozzolino dalam buku Reset Operasi Johanes Supranto (2009) "Operations research is the application of scientific method to the decision problems of business and other units of social organizations".

Menurut Richard I. Levin dan Charles A. Kirkpatrick dalam buku Reset Operasi Johanes Supranto (2009) "Operations research today refers to the application of scientific methodology of several different disciplines to problem related to the functioning or operationg of some unitbusiness, governmental, or institutional".

Riset operasi adalah penerapan suatu metode ilmiah di dalam suatu organisasi atau perusahaan secara terpadu untuk memecahkan masalah yang berkaitan dengan fungsi atau sistem organisasi, agar diperoleh hasil pemecahan masalah yang optimal, penjelasan ini disimpulkan berdasarkan dari definisi riset operasi menurut para ahli.

Linear Programming adalah suatu model umum yang dapat digunakan dalam pemecahan masalah pengalokasian sumber yang terbatas secara optimal.

\section{METODE PENELITIAN}

Penelitian ini merupakan hasil tinjauan pustaka serta kajian ilmiah untuk mengungkapkan masalah perhitungan komposisi bahan baku keramik, agar memperoleh hasil yang maksimal untuk bahan baku yang akan digunakan untuk produksi di PT White Horse Ceramic Indonesia. Metodologi yang digunakan adalah metodologi pengembangan sistem.

Metodologi pengembangan sistem yang digunakan adalah (SDLC) Systems Development Life Cycle, 'Siklus Hidup Pengembangan Sistem'. SDLC terdiri atas beberapa tahapan yaitu, rencana, analisis, desain, implementasi, uji coba dan pengelolaan. 


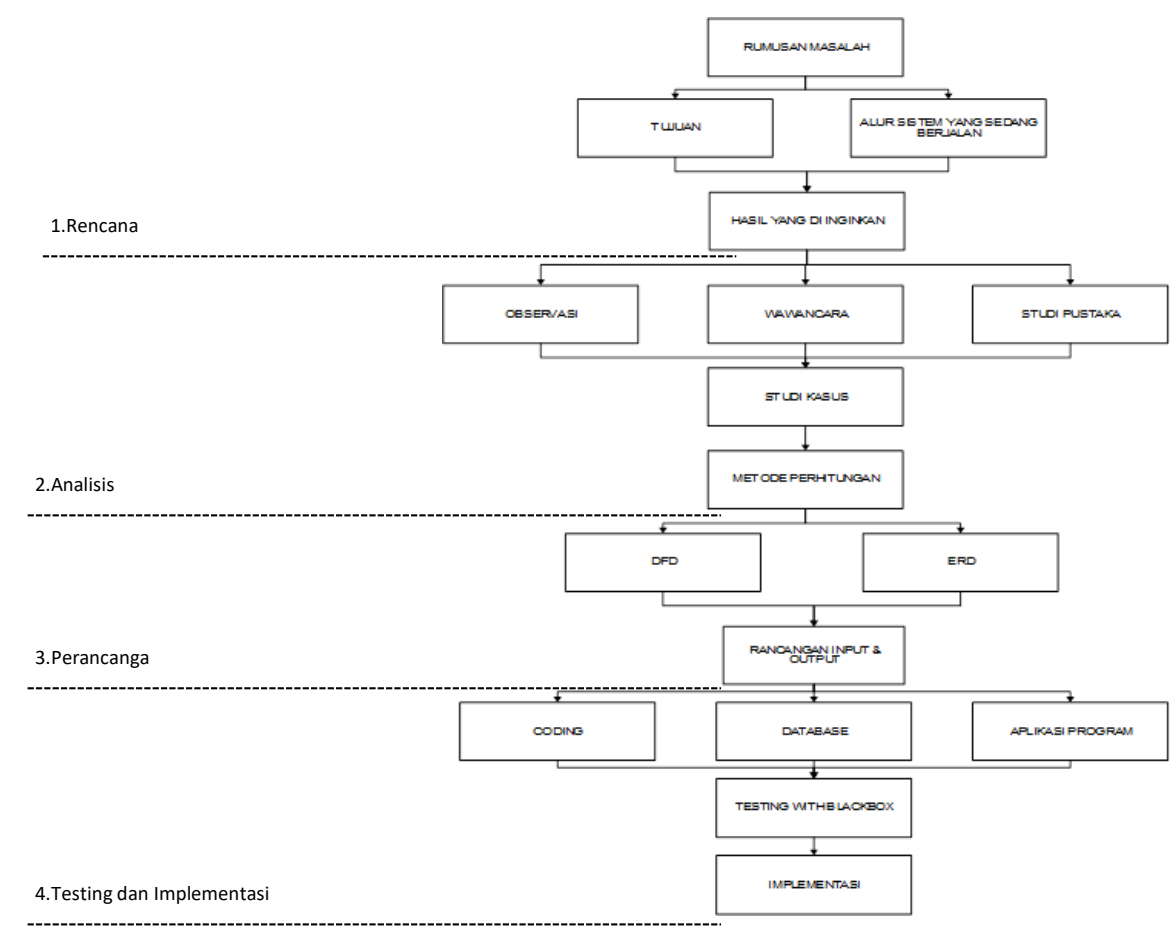

Gambar 1 Metodologi Penelitian

\section{PEMBAHASAN DAN HASIL}

Pembahasan penelitian ini di mulai dengan mengetahui Prosedur Sistem yang sedang Berjalan, yaitu

4.1 Pemasaran

a. Membuat Hasil Riset Pasar berdasarkan permintaan produk dari customer.

b. Menyerahkan Hasil Riset Pasar kepada divisi PPIC.

c. Menerima Working Order (WO) lembar 1.

4.2 PPIC

a. Menerima Hasil Riset Pasar dari Divisi Pemasaran.

b. Membuat WO rangkap 2 berdasar dari Hasil Riset Pasar.

c. Menyerahkan WO lembar 1 kepada divisi Pemasaran

d. Menghitung komposisi bahan baku sesuai $W O$.

e. Hasil perhitungan komposisi maka PPIC mendapatkan Bill of Material (BOM) dan Hasil Kebutuhan Bahan Baku (HKBB) rangkap 2 sesuai komposisi keramik yang akan diproduksi.

f. Menyerahkan HKBB lembar 2 kepada gudang raw material.

g. Menerima laporan ketidaktersediaan bahan baku, jika bahan baku tidak tersedia.

h. Jika bahan baku tidak tersedia maka membuat Purchase Requisition (PR) rangkap 2

i. Menyerahkan $P R$ Lembar 2 kepada divisi pembelian.

4.3 Gudang Raw Material

a. Menerima Hasil Kebutuhan Bahan Baku dari divisi PPIC.

b. Pengecekan ketersediaan bahan baku.

c. Jika material bahan baku tidak tersedia, diberikan kekurangannya kepada divisi PPIC.

d. Jika bahan baku tersedia maka selesai

4.4 Pembelian

Menerima dokumen PR Lembar 2 dari PPIC 


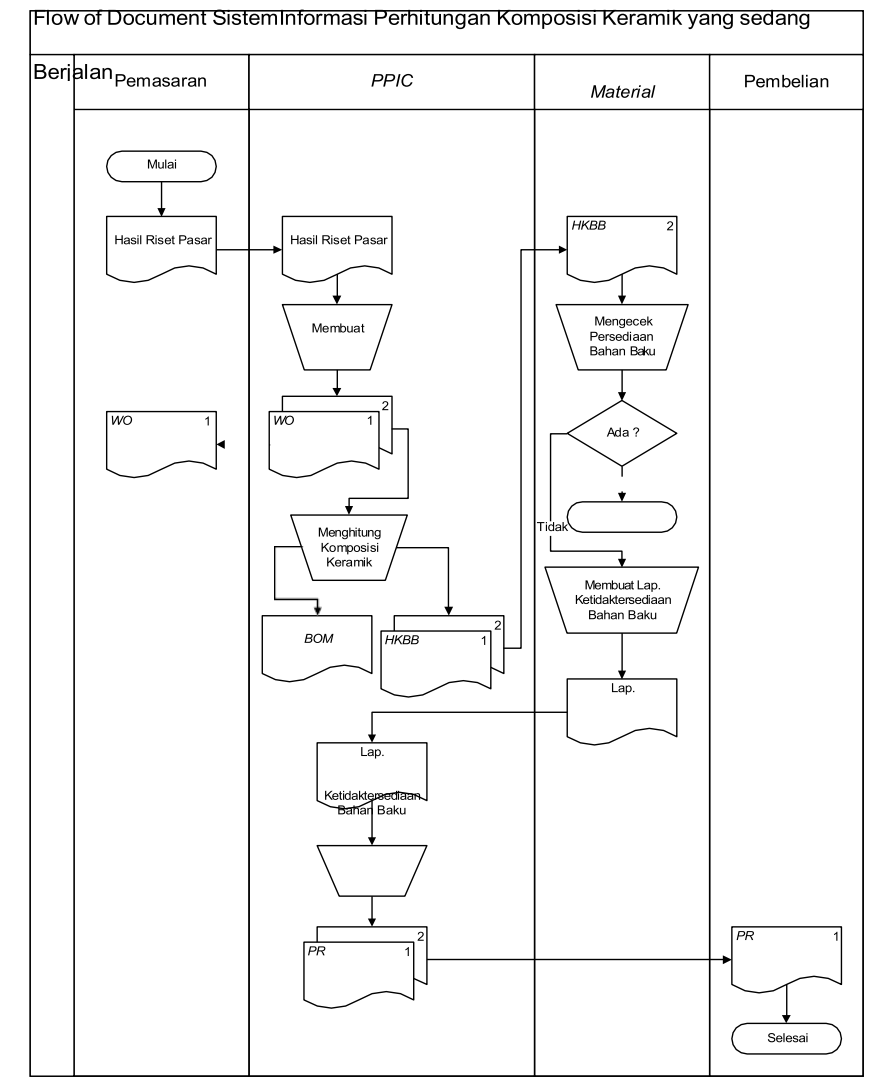

Gambar 2. Flow of Document Sistem Infornasi Perhitungan Komposisi Keramik yang sedang berjalan

\subsection{Temuan Masalah}

1. Sistem perhitungan komposisi bahan bakunya divisi PPIC masih menggunakan fasilitas Microsoft Excel dengan sangat sederhana.

2. Tidak bisa secara Realtime mengetahui kebutuhan bahan baku.

4.6 Akibat dari Permasalahan

1. Perhitungan komposisi tidak bisa dilakukan dengan segera atau Realtime

2. Proses produksi menjadi terlambat karena proses perhitungan komposisi dilakukan secara manual untuk perhitungan yang komplek.

PT White Horse Ceramic Indonesia ingin memproduksi dua macam tipe keramik yaitu keramik lantai dan dinding. Untuk memproduksi dua tipe produk tersebut masing-masing tipe memerlukan empat bahan baku yaitu body, engobe, glazure dan pasta. Bagaimana menentukan komposisi yang dapat memenuhi semua kriteria yang diinginkan dengan stok minimum persedian bahan baku sesuai tipe keramik per meter persegi, mengingat bahwa waktu kerja dan kandungan material tiap tipe keramiknya berbeda. Berikut adalah tabel material bahan baku keramik yang digunakan dan kapasitas persediaan material: Tabel 1 Material Bahan Baku yang Digunakan dan Kapasitas Persediaan Material 
Tabel 1 Material Bahan Baku yang Digunakan dan Kapasitas Persediaan Material

\begin{tabular}{|c|c|c|c|}
\hline $\begin{array}{c}\text { Jenis } \\
\text { Bahan } \\
\text { Baku \& } \\
\text { Persediaan }\end{array}$ & $\begin{array}{c}\text { Keramik } \\
\text { Lantai } \\
(\%)\end{array}$ & $\begin{array}{c}\text { Keramik } \\
\text { Dinding } \\
(\%)\end{array}$ & $\begin{array}{c}\text { Persediaan/ } \\
\text { (ton) }\end{array}$ \\
\hline Body & 45 & 50 & 100 \\
\hline Engobe & 25 & 20 & 90 \\
\hline Glazure & 20 & 25 & 75 \\
\hline Pasta & 10 & 5 & 20 \\
\hline
\end{tabular}

Tabel 2 Waktu Kerja dan Berat Kering

\begin{tabular}{|l|l|l|}
\hline Jenis Produk & Waktu Kerja/ & $\begin{array}{l}\text { Berat } \\
\text { Kering/ } \mathrm{m}^{2} \\
\text { (ton) }\end{array}$ \\
\hline Kenit & 5 \\
\hline Keramik Lantai & 150 & 3 \\
\hline
\end{tabular}

Berdasarkan komposisi bahan baku (Tabel 1) dan waktu kerja (Tabel 2) diperlukan adanya suatu sistem pendukung keputusan yang membantu pihak manajemen perusahaan dalam menemukan solusi yang optimal, yaitu menentukan komposisi masing-masing bahan yang diperlukan untuk membuat keramik dinding dan lantai dengan menggunakan jumlah kandungan bahan baku tertentu dan berat kering campuran yang sesuai dengan ukuran yang telah ditetapkan serta waktu kerja yang paling minimal.

Dalam masalah ini terdapat empat variabel keputusan yaitu:

1. $\mathrm{X} 1$, adalah variabel keputusan yang menunjukkan jumlah bahan baku body (dalam satuan persen) yang harus termasuk dalam komposisi keramik.

2. $\mathrm{X} 2$, adalah variabel keputusan yang menunjukkan jumlah bahan baku engobe (dalam satuan persen) yang harus termasuk dalam komposisi keramik.

3. X3, adalah variabel keputusan yang menunjukkan jumlah bahan baku glazure (dalam satuan persen) yang harus termasuk dalam komposisi keramik.

4. $\mathrm{X} 4$, adalah variabel keputusan yang menunjukkan jumlah bahan baku pasta (dalam satuan persen) yang harus termasuk dalam komposisi keramik.

Fungsi tujuan dan variabel keputusannya ditulis sebagai berikut:

$$
\text { Minimum } Z=100 \mathrm{X} 1+90 \mathrm{X} 2+75 \mathrm{X} 3+20 \mathrm{X} 4
$$

Di mana $\mathrm{Z}$ menunjukkan jumlah bahan baku yang dikeluarkan untuk proses produksi, sehingga nilai $\mathrm{Z}$ harus diminimalisasi. Koefisien dari masing-masing variabel keputusan adalah waktu penggilingan (dalam satuan menit) setiap bahan baku adalah:

1. Koefisien dari X1 menunjukkan persediaan bahan baku body adalah 100 ton.

2. Koefisien dari X2 menunjukkan persediaan bahan baku engobe adalah 90 ton.

3. Koefisien dari X3 menunjukkan persediaan bahan baku glazure adalah 75 ton.

4. Koefisien dari X4 menunjukkan persediaan bahan baku pasta adalah 20 ton.

Selanjutnya adalah pembentukan fungsi batasan, dalam hal ini merepresentasikan pedoman spesifikasi produk minimal yang harus sesuai dengan persediaan bahan yang ada. Misalnya untuk keramik lantai memiliki waktu kerja 150 menit dan berat bersih untuk produksi keramik dinding per meter perseginya adalah 5 ton. Sehingga dalam masalah ini terdapat dua batasan yang harus dipenuhi dan satu batasan tambahan yang harus dipenuhi dalam masalah pemograman linier, yaitu tidak ada variabel keputusan yang bernilai kurang dari 0. Dalam fungsi batasan aturan tersebut ditulis sebagai berikut: 


$$
\begin{gathered}
45 X 1+25 X 2+20 X 3+10 X 4>150 X 1+X 2+X 3+X 4=5 \\
X 1, X 2, X 3, X 4>0
\end{gathered}
$$

Fungsi batasan pertama menunjukkan bahwa keramik dinding harus memaksimumkan waktu produksi selama 150 menit dan koefisien pada tiap-tiap variabel keputusan menunjukkan bahan baku untuk keramik dinding, yaitu:

1. Koefisien dari X1 menunjukkan bahan baku body dalam keramik dinding adalah $45 \%$.

2. Koefisien dari X2 menunjukkan bahan baku engobe dalam keramik dinding adalah $25 \%$.

3. Koefisien dari X3 menunjukkan bahan baku glazure dalam keramik dinding adalah $20 \%$.

4. Koefisien dari X4 menunjukkan bahan baku pasta dalam keramik dinding adalah $10 \%$.

Fungsi batasan kedua menunjukkan bahwa berat kering total produk per meter persegi yang merupakan campuran dari keempat bahan tersebut, harus tepat 5 ton, dan batasan terakhir menunjukkan bahwa semua nilai variabel keputusan minimal 0.

Untuk menyelesaiakan masalah tersebut dengan metode simpleks maka semua batasan model harus dalam bentuk persamaan $(=)$, bukan pertidaksamaan $(\leq$ atau $\geq$ ). Agar semua batasan model dapat dituliskan dalam bentuk persamaan dan selanjutnya dapat dicari solusi awalnya maka fungsifungsi tersebut perlu sedikit dimodifikasi, menjadi:

$$
\text { Minimum } Z=100 \mathrm{X} 1+90 \mathrm{X} 2+75 \mathrm{X} 3+20 \mathrm{X} 4+0 \mathrm{~S} 1+0 \mathrm{~S} 2+\mathrm{MA} 1+\mathrm{MA} 2
$$

Dengan kendala:

$$
\begin{gathered}
45 \mathrm{X} 1+25 \mathrm{X} 2+20 \mathrm{X} 3+10 \mathrm{X} 4-\mathrm{S} 1+\mathrm{A} 1=150 \mathrm{X} 1+\mathrm{X} 2+\mathrm{X} 3+\mathrm{X} 4+\mathrm{A} 2=5 \\
\mathrm{X} 1, \mathrm{X} 2, \mathrm{X} 3, \mathrm{~S} 1, \mathrm{~S} 2, \mathrm{~A} 1, \mathrm{~A} 2 \geq 0
\end{gathered}
$$

Di mana S1 dan S2 adalah variabel penambah, yaitu untuk mengurangi surplus pada fungsifungsi tersebut dengan cara mengurangi fungsi tersebut dengan suatu variabel penambah. A1, dan A2 merupakan variabel buatan agar solusi awal dari masing-masing batasan dapat ditentukan, sedangkan $\mathrm{M}$ adalah sembarang bilangan positif yang nilainya sangat besar.

Masalah program linier pada umumnya memiliki n variabel yang tidak diketahui dari fungsi batasan, dan agar solusi awal bisa didapat maka sebanyak $n-m$ variabel harus dinolkan, dalam masalah ini terdapat 9 variabel yang tidak diketahui dengan 3 fungsi batasan, yang artinya kita harus memberi nilai nol terhadap 6 variabel. Variabel yang diberi nilai nol adalah X1, X2, X3, X4, S1 dan S2, dan variabel A1 dan A2 menjadi variabel dasar, sehingga persamaan-persamaan tersebut bisa diselesaikan.

$$
\begin{gathered}
45(0)+25(0)+20(0)+10(0)-0+\mathrm{A} 1=150 \text { sehingga nilai } \mathrm{A} 1=150 \\
0+0+0+0+\mathrm{A} 2=5 \text { sehingga nilai } \mathrm{A} 2=5
\end{gathered}
$$

Untuk menyelesaikan semua persamaan tersebut secara simultan dengan metode simpleks maka semua koefisien variabel pada fungsi tujuan dan batasan ditulis ke dalam bentuk tabel:

Perhitungan untuk baris $\mathrm{Zj}$ dengan cara menjumlahkan hasil kali $\mathrm{CJ}$ dengan masing-masing nilai koefisien dari fungsi batasan yang ada dalam baris yang sama, sedangkan $\mathrm{Cj}-\mathrm{Zj}$ adalah dihitung dengan cara mengurangkan masing-masing koefisien pada fungsi tujuan dengan nilai $\mathrm{Cj}$ yang ada dalam kolom yang sama. Solusi optimal dapat diperoleh apabila semua nilai pada baris $\mathrm{Zj}<0$ dan tidak ada variabel buatan yang muncul pada saat solusi optimal diperoleh.

Apabila masih ada nilai yang lebih besar dari nol maka kita pilih nilai yang paling positif sebagai kolom pemutar. Nilai quantity didapat dari hasil bagi nilai di kolom solusi masing-masing nilai yang ada pada kolom pemutar ditentukan dengan memilih baris yang nilai quantiti positif terkecil. Variabel yang dipilih sebagai kolom pemutar akan menjadi variabel dasar, dan variabel yang dipilih menjadi baris pemutar adalah variabel yang akan menjadi variabel bukan dasar. Baris baru variabel dasar didapt dari nilai pada baris yang lama dibagi bilangan pemutar (bilangan yang ada di persilangan baris pemutar dan kolom pemutar). Sedangkan baris lain dihitung dari nilai baris tabel lama dikurangi dengan hasil kali dari baris pemutar yang baru dengan nilai yang ada pada kolom pemutar pada baris yang sama. Hal itu dilakukan secara berulang sampai solusi optimal diperoleh.

Pada tabel iterasi keenam merupakan solusi paling optimal untuk masalah ini sudah bisa didapatkan, hal ini ditunjukkan dengan tidak adanya bilangan pada garis $\mathrm{Cj}$ - $\mathrm{Zj}$ yang bernilai positif dan bernilai nol. Hasil dari perhitungan ini menunjukkan bahwa keramik dinding yang dapat 
dihasilkan adalah 33,4 meter persegi $(0.3333$ x100) dengan persediaan bahan baku yang tersedia. Sedangkan untuk keramik lantai dengan persediaan bahan baku yang ada menghasilkan 334 meter persegi $(3,3333 \times 100)$. Untuk kedua tipe keramik tersebut menggunakan bahan baku sebanyak 545 ton.

Setelah melalui tahap perencanaan dan analisis, kemudian tahap perancangan sistem dengan menggunakan flow of system, Data Flow Diagram (DFD) dan Enhanced Entity Relationship (EER), yaitu dengan merancang sistem informasi yang akan diusulkan.

1. Pemasaran

a. Membuat Hasil Riset Pasar berdasarkan permintaan produk dari customer.

b. Menyerahkan Hasil Riset Pasar kepada divisi PPIC.

c. Menerima Working Order (WO) lembar 1.

2. $P$ PIC

a. Menerima Hasil Riset Pasar dari Divisi Pemasaran.

b. Memasukan data Hasil Riset Pasar sebagai dasar pembuatan $W O$, kemudian disimpan pada $\mathrm{Db}$ SPK

c. Mencetak $W O$ rangkap 2.

d. Menyerahkan $W O$ lembar 1 kepada divisi Pemasaran

e. Menghitung komposisi bahan baku sesuai $W O$.

f. Perhitungan komposisi berdasarkan $W O$, kemudian disimpan ke Db_SPK

g. Mencetak Hasil Kebutuhan Bahan Baku (HKBB) rangkap 2 sesuai komposisi keramik yang akan diproduksi.

h. Menyerahkan HKBB lembar 2 kepada gudang raw material.

i. Menerima laporan ketidaktersediaan bahan baku, jika bahan baku tidak tersedia.

j. Jika bahan baku tidak tersedia maka membuat Purchase Requistion $(P R)$ rangkap 2

k. Menyerahkan $P R$ Lembar 2 kepada divisi pembelian.

3. Gudang Raw Material

a. Menerima hasil kebutuhan material bahan baku dari divisi PPIC.

b. Mengcek ketersediaan bahan baku.

c. Jika material bahan baku tidak tersedia, diberikan kekurangannya kepada divisi PPIC.

4. Pembelian

a. Menerima dokumen $P R$ dari PPIC jika stock material yang di perlukan kurang.

b. Membeli bahan baku sesuai dengan $P R$. 


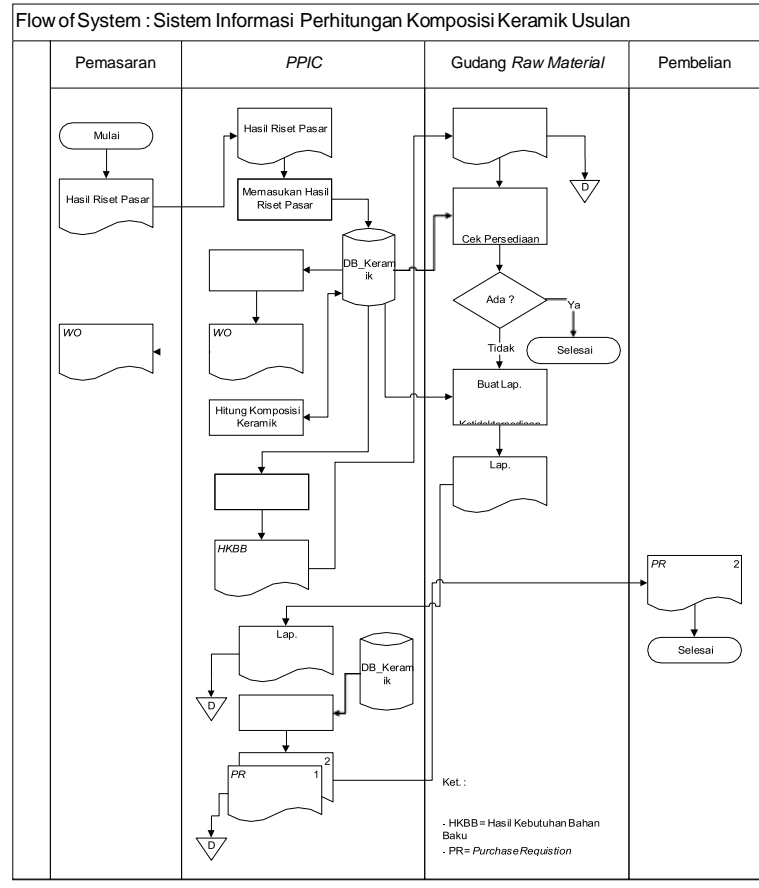

Gambar 3 Flow of System Sistem Informasi Perhitungan Komposisi Keramik Ususlan

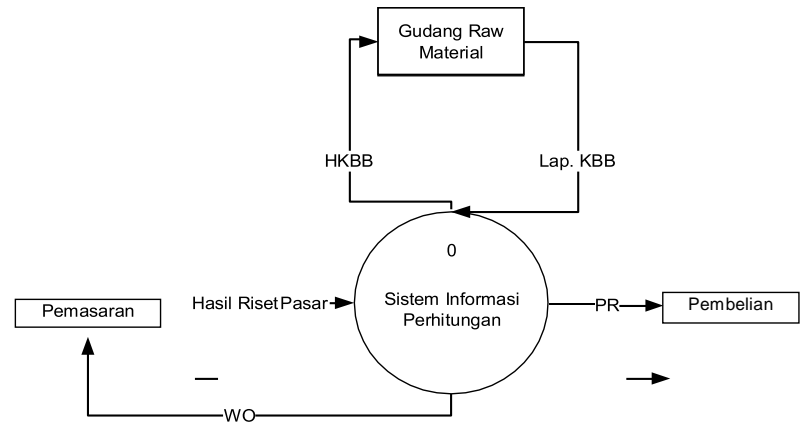

Gambar 4 DFD Level 0 Sistem Informasi Perhitungan Komposisi Keramik

Keterangan:

HKBB: Hasil Kebutuhan

Bahan Baku Lap. KBB:

Lap. Kebutuhan Bahan

Baku WO: Work Order

PR: Purchase Requistion

Hubungan antar entitas dalam sistem ini dijabarkan dengan menggunakan Entity Relationship Diagram (ERD) atau Enhance Entity Relationship (EER), sebagai berikut: 


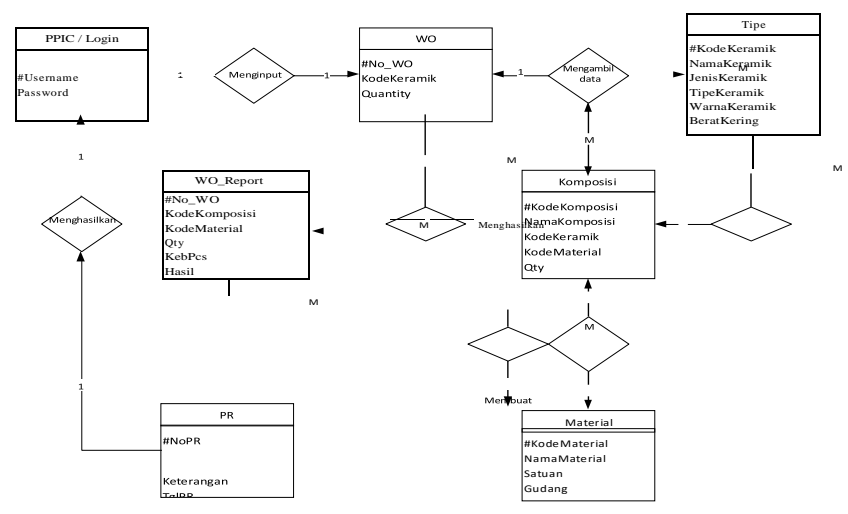

Gambar 5 EER (Enhanced Entity Relationship) Sistem Informasi Komposisi Bahan Baku Keramik

\section{KESIMPULAN DAN SARAN \\ 5.1 Kesimpulan}

Berdasarkan penelitian yang dilakukan pada PT. White Horse Ceramic Indonesia mengenai Sistem Perhitungan Komposisi Keramik, maka penulis mengambil kesimpulan sebagai berikut:

Dalam proses perhitungan komposisi keramik yang sekarang dilakukan PT. White Horse Ceramic Indonesia masih belum maksimal penggunaannya, sehingga mengakibatkan lambatnya proses perhitunganserta kurang akuratnya hasil kebutuhan bahan baku yang akan digunakan pada saat produksi, apabila dibiarkan dapat mengakibatkan terlambatnya proses produksi dan merugikan perusahaan jika dibiarkan terus menerus. Dengan menggunakan Aplikasi Sistem Pendukung Keputusan Keramik ini, perhitungan komposisi keramik akan lebih akurat karena menggunakan perhitungan dengan metode simpleks, metode ini memecahkan permasalahan dari pemecahan dasar yang fleksibel, dilakukan secara berulang-ulang sampai memperoleh hasil yang optimal. Sehingga secara otomatis menjadikan perhitungan komposisi ini lebih efesien dan efektif.

\section{Saran}

Berdasarkan pembahasan dari hasil penelitian yang dilakukan, saran yang dapat dilaksanakan adalah sebagai berikut:

1. Untuk meningkatkan efektifitas, maka perusahaan disarankan mengembangkan Sistem Pendukung Keputusan untuk membantu saat perhitungan komposisi bahan baku keramik.

2. Dengan diterapkannya sistem pendukung keputusan yang terintegrasi dengan baik, diharapkan akan membantu proses perhitungan komposisi bahan baku dapat dilakukan secara cepat dan tepat, sehingga dapat meningkatkan efektifitas waktu.

\section{DAFTAR PUSTAKA}

Djaja, Iman Suwidodo. 2005. Pemograman SQL dalam Database Server MySQL. Yogyakarta: Andi Fatharani Hana dkk, 2013. Makalah Tentang Bahan Keramik

http://www.rumahbangun.com/ukuran-material-keramik-bangunan-dan-kegunaanya Kadir, Abdul. (2003) Pengenalan Sistem Informasi, hal 10,31,54, 64. Yogyakarta: ANDI

Kadir, Abdul. 2008. Tuntutan Praktis: Belajar Database Menggunakan MySQL, Yogyakarta: ANDI Kadir, Abdul. 2009. Dasar Perancangan dan Implementasi Database Relasional. Yogyakarta: Andi Kahar, Novhirtamely, 2010. Aplikasi Linear Programming: Metode Simpleks Fungsi Tujuan Maksimisasi Untuk Menentukan Jumlah Produksi Parcel Hari Raya Idul Fitri. Hal 5-7 Jambi: STMIK Nurdin Hamzah

Ketut Darmayuda, 2010. Pemrograman Aplikasi Database dengan Microsoft Visual Basic.NET 2008. Bandung: Informatika Bandung

Kristanto, Andri. (2003). Perancangan Sistem Informasi dan Aplikasinya, Yogyakarta: Gava Media Pangestu Subagio, dkk. DASAR-DASAR OPERATIONS RESEARCH.edisi2 BAB2 Hal. 9 - 32 SACMI IMOLA, 2002. Applied Ceramic Technology Vol.1. Italy: Editrice La Mandragora s.r.1 http://www.slideshare.net/eko123/kliping-seni-rupa-terapan-keramik

Supranto, Johanes. 2009. Riset Operasi. Jakarta: Universitas Indonesia

Turban, Efraim, McClean, Ephraim, Wetherbe, James. 1999. Information Technology for Management Making Coinnections for Strategis Advantage. $2^{\text {nd }}$ Edition, New Jersey, John Wiley \& Sons, Inc.

Wahana Komputer ,2009. ShortCourse: Visual Basic 2008. Yogyakarta: Andi 